\title{
ALLOCATING FINANCIAL RESOURCES FOR COMPETITIVE PROJECTS USING A ZERO SUM GAINS DEA MODEL
}

Eliane Gonçalves Gomes ${ }^{1}$

Geraldo da Silva e Souza ${ }^{2}$

\begin{abstract}
In this paper we use a Zero Sum Gains Data Envelopment Analysis model (ZSG-DEA) to allocate financial resources for competitive projects managed by the Brazilian Agricultural Research Corporation (Embrapa) research centers. The initial output measurement in the production process modeled is the amount of financial resources available, uniformly distributed among research centers. The input variables are proxies for the intensity of projects externally funded, quality of project management, and level of participation in complex researches. The allocation proposed has maximum global efficiency.
\end{abstract}

Key-words: Resource allocation; Efficiency; DEA; Zero Sum Gains.

Resumo: Neste artigo foi usado um modelo de Análise de Envoltória de Dados com Ganhos de Soma Zero (DEA-GSZ) para alocar recursos financeiros a projetos competitivos gerenciados pelos centros de pesquisa da Empresa Brasileira de Pesquisa Agropecuária (Embrapa). A medida inicial de output modelada neste processo de produção é o total de recursos financeiros disponível, distribuído uniformemente entre os centros de pesquisa. As variáveis de input são proxies para formalização de projetos com captação externa de recursos, gestão de projetos e participação em esforço complexo de pesquisa. Os resultados obtidos são os que geram a alocação de recursos mais eficiente.

Palavras-chave: Alocação de recursos; Eficiência; DEA; Ganhos de Soma Zero.

\section{INTRODUCTION}

The Brazilian Agricultural Research Corporation (Embrapa) uses Macro Programs (MPs) to manage its research and administrative projects. Each MP comprises several projects and the financial resources to carry them out. They act as control instruments regarding execution of the strategic plans established for the company as a whole and for the research centers in particular. Embrapa has 37 research centers spread all over the country. There is a total of six MPs, labeled MP1-MP6, dealing with projects of distinct natures and complexities.
In this article we are concerned with resource allocation within MP3. This Macro Program is known as Incremental Technological Development of Agribusiness and contemplates specific assistance to local research programs in the context of a research center. The idea is that within the research center the allocation of resources should be responsibility of the research center. Overall qualification of resources and its distribution among research centers is under the control of the company headquarters. The objective of this article is to describe a model that provides an efficient way to allocate funds to the research centers once the total budget of the

\footnotetext{
1 Brazilian Agricultural Research Corporation, SGE, Av. W3 Norte final, 70770-901, Brasília, DF, Brazil, eliane.gomes@embrapa.br

2 Brazilian Agricultural Research Corporation, SGE, Av. W3 Norte final, 70770-901, Brasília, DF, Brazil, geraldo.souza@embrapa.br
} 
program has been determined. We propose the use of mathematical programming and DEA in this endeavor. Similar approaches can be seen in Cooper et al. (2000), Yan et al. (2002), Beasley (2003), Gomes (2003), Lins et al. (2003), Lozano and Villa (2004), Korhonen and Syrjänen (2004), Avellar et al. (2005, 2007), Gomes et al. (2005, 2007). In Soares of Mello et al. (2006) there is a revision on the theme. We are particularly interested in the models with the property of sum of gains zero, known as DEA-ZSG (Zero Sum Gains DEA models) described in Gomes (2003), Lins et al (2003), Gomes et al (2005, 2007) and Gomes and Lins (2008). The interesting property of a typical DEA-ZSG application is that it optimizes the allocation leaving the total resource unchanged.

\section{DATA ENVELOPMENT ANALYSIS}

Consider a production process with $n$ production units. Each unit uses variable quantities of $m$ inputs to produce varying quantities of $s$ different outputs $y$. Denote by $Y=\left(y_{1}, \ldots, y_{n}\right)$ the $s \times n$ production matrix of the $n$ production units and by $X=\left(x_{1}, \ldots, x_{n}\right)$ the $m \times n$ input matrix. Notice that the element $y_{r} \geq 0$ is the $s \times 1$ output vector of unit $r$ and $x_{r} \geq 0$ is the $m \times 1$ vector of inputs used by unit $r$ to produce $y_{r}$ (the condition $l \geq 0$ means that at least one component of $l$ is strictly positive). The matrices $Y=\left(y_{i j}\right)$ and $X=\left(x_{i j}\right)$ must satisfy: $\sum_{i} p_{i j}>0$ and $\sum_{j} p_{i j}>0$, where $p$ is $x$ or $y$. The measure of technical efficiency of production of unit $o$ under the assumption of variable returns to scale and output orientation is given by the solution of the linear programming problem $\operatorname{Max} \phi, \lambda \phi$ $\operatorname{Max}_{f, f} f$ subject to the restrictions

1. $\lambda=\left(\lambda_{1}, \ldots, \lambda_{n}\right) \geq 0$ and $\sum_{i}^{n} \lambda_{i}=1$

2. $Y \lambda \geq \phi y_{o}$

3. $X \lambda \leq x_{o}$

A unit is considered efficient if $\operatorname{Max} \phi, \lambda \phi=1$. If a unit is not efficient it can be projected to an efficient unit, adjusting its production vector by the (radial) factor $\operatorname{Max} \phi, \lambda \phi$.

Similar concepts can be defined for constant returns to scale, relaxing condition (1), and for input orientation. See Coelli et al. (2005).
The DEA problem presented here is known as the envelope problem. Its dual is known as the multiplier problem.

\section{ZERO SUM GAINS DEA MODELS (DEA-ZSG)}

The classic DEA models assume total freedom of production. In other words, the production process of a production unit doesn't interfere in the production of other units. However, in some cases there is not such freedom. When total resources available are fixed, if a unit produces more it will imply reduction in the production of other units. This is the case, to mention a simple case, when one evaluates efficiency of countries competing for medals in the Olympic Games. Making a country efficient by improving his achievements in medals will interfere with the winnings of other countries. DEA-ZSG models were proposed in the literature to assist in this type of problems.

The idea is to obtain the best possible projections of inputs or outputs without changing the total resources available for distribution among the units under evaluation. Leaving the total resource unchanged implies no net gains in the system. The DEA-ZSG model is considered in detail in Gomes (2003).

There are several ways or strategies for an inefficient unit to go after its target under these conditions. Strategies to search targets are proposed in Lins et al. (2003), the proportional reduction strategy being of special interest: units searching efficiency (trying to reach the frontier) must shed input units. So the sum is kept constant, the inputs acquired by other units must be proportional to their input level. This means that the lower the input level of a unit, the lesser the inputs it acquires. What has just been said applies to the outputs: the higher the output level, the higher the outputs it looses.

There is always the possibility of more than one unit trying to maximize efficiency. This can either be done in competition or cooperation (Brandenburger and Nalebuff, 1996). The7ase in which the units create a cooperative group is the most interesting case in ZSG modeling. In the DEA-ZSG paradigm, cooperative search for efficiency means that the units belonging to the group try to allocate a given quantity of input only 
to those units that do not belong to the group, the same applying when the group tries to withdraw a given quantity of outputs only from those units that do not belong to the group, either.

In the general case of multiple units acting in cooperation, the DEA-ZSG model becomes a Multi-objective Nonlinear Programming Problem (Gomes, 2003). Problems like this tend to lead often to the use of metaheuristics owing to the large number of variables and units. However, for the proportional reduction strategy, Gomes (2003) prove that the model is reduced to a Mono-objective Nonlinear Programming Problem in accordance with the Proportional Efficiencies in the Proportional Strategies Theorem. The Theorem establishes that if various cooperating units search targets following proportional strategies, the efficiencies of the units in the DEA-ZSG model are directly proportional to their efficiencies in the classical model.

Should all inefficient units gather in a sole cooperative group and search for their efficiency in the classic DEA efficiency frontier, the use of DEA-ZSG will lead to the complete constant sum input (or output) reallocation. After this reallocation, all units will belong in the efficient frontier, i.e., they all will be $100 \%$ efficient.

This new DEA frontier, herein named uniform DEA frontier or maximum efficiency frontier, will be located at lower levels than those of the DEA classic model frontier. This happens because efficient units lose efficiency, as they end up having more input units and/or less output units. This is so to compensate for the inverse movement in the previously inefficient units in order to keep constant the sum of either the inputs or outputs. This maximum efficiency maybe seen as "ideal" by regulating organs as the decision maker will be presented with an input and/or output reallocation that makes all units be $100 \%$ efficient.

To build directly a uniform frontier in which inefficient units are joined in a single cooperative grouping $W$, Gomes (2003) have proved the Target Determination Theorem. This theorem establishes that "the unit target being studied in the proportional strategy DEA-ZSG model equals the classic target multiplied by the reduction coefficient". Together with the Proportional Efficiencies in the Proportional Strategies Theorem, the Target Determination Theorem leads to the solution of the Non Linear Programming Problem being a single equation.
Thus, for both the CCR and BCC input oriented models, equation (1) is valid. In it, $h_{R i}$ and $h_{i}$ are the respective efficiencies of the DEAZSG and classic DEA models; $W$ is the cooperating units group; $r_{i j}=h_{i-I} / h_{j-I}$ is the proportionality factor resulting from the use of the input oriented proportional strategy. Equation (2) is the corresponding equation for output-oriented models in $q_{i j}=h_{i-O} / h_{j-O}$ is the proportionality factor.

$$
\begin{aligned}
& h_{R i}=h_{i}\left(1+\frac{\sum_{j \in W}\left[x_{j}\left(1-r_{i j} h_{R i}\right)\right]}{\sum_{j \notin W} x_{j}}\right) \\
& h_{R i}=h_{i}\left(1-\frac{\sum_{j \in W}\left[y_{j}\left(q_{i j} h_{R i}-1\right)\right]}{\sum_{j \notin W} y_{j}}\right)
\end{aligned}
$$

In our particular application it has a simple structure in terms of the classical DEA presented in the previous section that we will explore here. Suppose that one wants to allocate a fixed amount of resource $R$ among $n$ units based on given inputs $x$. In this context one can consider an initial model in which, regardless of the input level, to each unit is allocated the amount $R / n$. Thus one now consider a DEA model with constant output and inputs $x$. Let $\phi_{o}^{*}$ be the efficiency of unit $o$ in this model. The final projection $\left(\phi_{o}^{*} / \sum_{o} \phi_{o}^{*}\right) R$ is DEA-ZSG efficient. This solution can be shown to be invariant under scale and orientation of the DEA model.

\section{INPUTS AND TOTAL BUDGET}

As inputs for the allocation of resources we considered three indicators: Externally funded projects over total projects (X1), Relative participation of the unit in MP3 (X2) and relative participation of the unit in complex programs (X3). Complex programs are defined by MPs 1, 2, 3 and 6 . To compute the relative participation in complex programs the projects of MP1 and MP2 are given weight 2 and projects in MP3 and MP6 weight 1. A ratio is computed relative to the total number of projects under responsibility of the unit using the weighted sum in the numerator. The pertinent data on those variables are shown in Table 1, for the 
37 Embrapa's research centers. The total budget for the macro program is $\mathrm{R} \$ 1,000,000.00$.

\section{RESULTS}

Results are shown in Table 1. It is seen that the new allocation is DEA efficient. It is necessary only one iteration to achieve these results.

It should be pointed out here that variations of the proposed model can be considered in the presence of classification variables. For example if type is a classification of concern one may perform an analysis in two stages. Firstly, one compute efficiency measures within groups. After projecting within groups we consider an overall DEA model using as outputs the group projections. This order of ideas is based on the work of Brocket and Golany (1996).

As can be seen in Table 1, some of the inputs have zero values. It is important to mention that the DEA-ZSG approach deals with the zero variables similarly to the classical DEA models.

In this model the inefficent DMUs are the ones with potential not covered completely by the uniform distribution of the resources. The projection onto the efficient frontier embeds problems of surpluses and shortages (as the total amount is constant), and was solved through the DEA-ZSG solution. This produces the maximum global efficeny.

\section{FINAL CONSIDERATIONS}

The use of DEA-ZSG was quite appropriate to allocate funding for Embrapa's research centers within MP3. The allocation proposed was better than any other proposed by administrators taking into account the input variables, in the sense of producing a greater average efficiency of the system. No subjective considerations other than the definition of criteria were necessary to achieve this result.

The results were well received in the company's administration. They were presented in a workshop, when it was discussed the resource allocation strategy change within the MP3 (decentralization). The invited researchers said that the proposed approach and the results were very interesting. However they were still not implemented, since the resources distribution to this MP is still done as previously, i.e., by project instead of by research center, as the decentralization proposal suggested.

\section{REFERENCES}

AVELLAR, J.V.G.; MILIONI, A.Z. \& RABELLO, T.N. Modelos DEA com variáveis limitadas ou soma constante. Pesquisa Operacional Vol. 25, n. 1, p. 135-150, 2005.

AVELLAR, J.V.G.; MILIONI, A. Z. \& RABELLO, T.N. Spherical frontier DEA model based on a constant sum of inputs. Journal of the Operational Research Society Vol. 58, p. 1246-1251, 2007.

BEASLEY, J.E. Allocating fixed costs and resources via data envelopment analysis. European Journal of Operational Research Vol. 147, p. 198-216, 2003.

BRANDENBOURGER A.M.; NALEBUFF B.F. Co-Opetition: a revolutionary mindset that combines competition and cooperation. Broadway Business: New York. 1997.

BROCKET, P.L. \& GOLANY, B. Using ranking statistics for determining programmatic efficiency differences in data envelopment analysis. Management Science Vol. 42, p. 466-472, 1996.

COELLI, T.J., PRASADA, D.S. \& O'DONNELL, C.J. An Introduction to Efficiency and Productivity Analysis. $2^{\text {nd }}$ Edition. New York: Springer, 2005.

COOPER, W.W., SEIFORD, L.M. \& TONE, K. Data Envelopment Analysis: a comprehensive text with models, applications, references and DEA-solver software. Boston: Kluwer Academic Publishers, 2000.

GOMES, E.G. \& LINS, M.P.E. Modelling undesirable outputs with zero sum gains data envelopment analysis models. Journal of the Operational Research Society Vol. 59, p. 616-623, 2008.

GOMES, E.G. Modelos de Análise de Envoltória de Dados com Ganhos de Soma Zero (Zero Sum Gains DEA models). Ph.D. Dissertation. Rio de Janeiro, Brasil. 2003. 
GOMES, E.G., SOARES DE MELLO, J.C.C.B. \& LINS, M.P.E. Uniformização da fronteira eficiente em modelos de análise de envoltória de dados com ganhos de soma zero e retornos constantes de escala. Pesquisa Operacional Vol. 25, n. 2, p. 261-277, 2005.

GOMES, E.G., SOUZA, G.S., LIMA, S.M.V. \& FONSECA, C.E.L. Alocação de bolsas de iniciação científica às unidades da Embrapa com modelos de Análise Envoltória de Dados com Ganhos de Soma Zero. Engevista Vol. 9, 2007.

KORHONEN, P. \& SYRJÄNEN, M. Resource allocation based on efficiency analysis. Management Science Vol. 50, n. 8, p. 1134-1144, 2004.

LINS, M.P.E., GOMES, E.G., SOARES DE MELLO, J.C.C.B. \& SOARES DE MELLO,
A.J.R. Olympic ranking based on a Zero Sum Gains DEA model. European Journal of Operational Research Vol. 148, n. 2, p. 312-322, 2003.

LOZANO, S.N. \& VILLA, G. Centralized resource allocation using data envelopment analysis. Journal of Productivity Analysis Vol. 22, p. 143-161, 2004.

SOARES DE MELLO, J.C.C.B., GOMES, E.G, LETA, F.R. \& SOARES DE MELLO, M.H.C. Algoritmo de alocação de recursos discretos com análise de envoltória de dados. Pesquisa Operacional Vol. 26, p. 225-239, 2006.

YAN, H., WEI, Q. \& HAO, G. DEA models for resource reallocation and production input/output estimation. European Journal of Operational Research Vol. 136, p. 19-31, 2002. 
Table 1 - Data and results

\begin{tabular}{|c|c|c|c|c|c|c|c|}
\hline Units & $\mathrm{X} 1$ & $\mathrm{X} 2$ & $\mathrm{X} 3$ & $\begin{array}{c}\text { Initial Endowment } \\
\mathrm{R} \$\end{array}$ & $\begin{array}{l}\text { Efficiency } \\
\text { (initial) }\end{array}$ & $\begin{array}{c}\text { Proposed allocation } \\
\text { R\$ }\end{array}$ & $\begin{array}{c}\text { Efficiency } \\
\text { (final) }\end{array}$ \\
\hline Unit01 & 19.35 & 9.45 & 50.00 & $27,027.03$ & 0.2070 & $56,662.32$ & 1.0000 \\
\hline Unit02 & 8.70 & 1.38 & 44.44 & $27,027.03$ & 1.0000 & $11,731.54$ & 1.0000 \\
\hline Unit03 & 32.43 & 4.33 & 40.00 & $27,027.03$ & 0.4167 & $28,155.67$ & 1.0000 \\
\hline Unit04 & 4.35 & 5.51 & 66.67 & $27,027.03$ & 0.3667 & $31,995.07$ & 1.0000 \\
\hline Unit05 & 20.93 & 6.50 & 55.56 & $27,027.03$ & 0.2845 & $41,232.15$ & 1.0000 \\
\hline Unit06 & 8.70 & 3.35 & 50.00 & $27,027.03$ & 0.5238 & $22,396.55$ & 1.0000 \\
\hline Unit07 & 46.67 & 2.95 & 25.00 & $27,027.03$ & 0.6197 & $18,930.44$ & 1.0000 \\
\hline Unit08 & 8.33 & 3.15 & 0.00 & $27,027.03$ & 0.6875 & $17,064.05$ & 1.0000 \\
\hline Unit09 & 38.24 & 3.54 & 55.56 & $27,027.03$ & 0.4562 & $25,714.59$ & 1.0000 \\
\hline Unit10 & 6.45 & 4.72 & 58.33 & $27,027.03$ & 0.4079 & $28,761.17$ & 1.0000 \\
\hline Unit11 & 0.00 & 4.33 & 40.00 & $27,027.03$ & 0.5000 & $23,463.07$ & 1.0000 \\
\hline Unit12 & 50.00 & 0.00 & 100.00 & $27,027.03$ & 1.0000 & $11,731.54$ & 1.0000 \\
\hline Unit13 & 21.43 & 3.54 & 10.00 & $27,027.03$ & 0.5759 & $20,370.22$ & 1.0000 \\
\hline Unit14 & 44.44 & 4.33 & 33.33 & $27,027.03$ & 0.4286 & $27,373.61$ & 1.0000 \\
\hline Unit15 & 2.86 & 6.50 & 37.50 & $27,027.03$ & 0.3206 & $36,596.32$ & 1.0000 \\
\hline Unit16 & 47.06 & 1.38 & 50.00 & $27,027.03$ & 0.8800 & $13,331.29$ & 1.0000 \\
\hline Unit17 & 6.45 & 3.35 & 83.33 & $27,027.03$ & 0.5509 & $21,295.65$ & 1.0000 \\
\hline Unit18 & 5.26 & 3.74 & 57.14 & $27,027.03$ & 0.5135 & $22,845.60$ & 1.0000 \\
\hline Unit19 & 5.00 & 3.74 & 66.67 & $27,027.03$ & 0.5164 & $22,716.52$ & 1.0000 \\
\hline Unit20 & 18.18 & 3.35 & 0.00 & $27,027.03$ & 0.6471 & $18,130.55$ & 1.0000 \\
\hline Unit21 & 18.18 & 2.17 & 16.67 & $27,027.03$ & 0.8571 & $13,686.79$ & 1.0000 \\
\hline Unit22 & 7.69 & 5.31 & 50.00 & $27,027.03$ & 0.3602 & $32,569.33$ & 1.0000 \\
\hline Unit23 & 24.62 & 7.68 & 28.57 & $27,027.03$ & 0.2610 & $44,945.49$ & 1.0000 \\
\hline Unit24 & 13.95 & 5.51 & 50.00 & $27,027.03$ & 0.3356 & $34,953.68$ & 1.0000 \\
\hline Unit25 & 24.24 & 5.51 & 28.57 & $27,027.03$ & 0.3532 & $33,213.96$ & 1.0000 \\
\hline Unit26 & 11.11 & 3.15 & 0.00 & $27,027.03$ & 0.6875 & $17,064.05$ & 1.0000 \\
\hline Unit27 & 0.00 & 3.54 & 0.00 & $27,027.03$ & 0.6111 & $19,197.06$ & 1.0000 \\
\hline Unit28 & 27.27 & 4.33 & 50.00 & $27,027.03$ & 0.4000 & $29,328.84$ & 1.0000 \\
\hline Unit29 & 47.83 & 4.53 & 33.33 & $27,027.03$ & 0.4125 & $28,440.09$ & 1.0000 \\
\hline Unit30 & 33.33 & 4.13 & 62.50 & $27,027.03$ & 0.3946 & $29,728.77$ & 1.0000 \\
\hline Unit31 & 16.13 & 4.13 & 62.50 & $27,027.03$ & 0.4092 & $28,669.03$ & 1.0000 \\
\hline Unit32 & 4.55 & 5.51 & 20.00 & $27,027.03$ & 0.3686 & $31,826.16$ & 1.0000 \\
\hline Unit33 & 35.38 & 7.48 & 39.47 & $27,027.03$ & 0.2598 & $45,157.94$ & 1.0000 \\
\hline Unit34 & 23.81 & 7.09 & 25.00 & $27,027.03$ & 0.2839 & $41,327.00$ & 1.0000 \\
\hline Unit35 & 23.08 & 4.72 & 40.00 & $27,027.03$ & 0.3873 & $30,288.69$ & 1.0000 \\
\hline Unit36 & 0.00 & 2.17 & 0.00 & $27,027.03$ & 1.0000 & $11,731.54$ & 1.0000 \\
\hline Unit37 & 34.21 & 4.33 & 33.33 & $27,027.03$ & 0.4286 & $27,373.61$ & 1.0000 \\
\hline Total & & & & $1,000,000.00$ & & $1,000,000.00$ & \\
\hline
\end{tabular}

